\title{
The Effect of Mainstreaming Children with Autism in Public Education on Reduced ADHD Behavior
}

\author{
Dr. Abdallah Makhadmah \\ Head of Social Services, Ministry of Justice, the Hashemite Kingdom of Jordan
}

\begin{abstract}
This study investigated the effect of mainstreaming children with autism in normal population on reduced ADHD behavior. Using a quasi-experimental design approach, the researcher applied the study on a sample consisted of 60 students assigned to experimental $(n=30)$ and control $(n=30)$ groups. The study instruments were tested for reliability and validity and used to collect date for analysis. Findings showed differences between the experimental and control groups on posttest measurement with differences being in favor of the experimental group. Similarly, results revealed differences between pretest and posttest for both groups in terms of reduction of ADHD behavior in favor of the posttest measurement. As for the effect of mainstreaming children with autism in normal classes on reduced ADHD symptoms, results showed differences by group (.001), in favor of the experimental group, compared with no differences in reduced ADHD symptoms on the pretest (.603) implying equivalence of both groups on the pretest measurement.
\end{abstract}

Keywords: Mainstreaming, ADHD, Autism, Attention Deficit

DOI: $10.7176 / \mathrm{JEP} / 11-21-04$

Publication date:July $31^{\text {st }} 2020$

\section{Introduction}

Teaching process necessitates an instruction environment rich with stimuli to stimulate student curiosity and encourage learning. This requires a classroom teacher to be alert to and have the skills to identify any behavioral problems that impede their learning. Students in normal classroom do not learn at the same level, and learning difficulties may differ in intensity and degree, for instance there would be students with autism, learning difficulty, behavioral adaptability and other problems that may affect

Autism children may have excessive activity or idle and both considered a problem in classroom and impede learning (Al Rousan, 2007). Teaching strategies used by teacher in classroom must take care of student differences, and respond to any behavioral problems students may have in order to facilitate and motivate their learning and supporting their participation in activities (Al Ellan \& Al Dibsi, 2012). Mainstreaming of children with autism in normal classes is used to facilitate student learning and improve adaptability of students with special needs. The current study seeks to investigate the effectiveness of mainstreaming strategy in reducing attention deficit hyperactivity behaviors among autism children.

Based on the literature reviewed, the researcher found dearth of studies addressed mainstreaming autism children diagnosed with ADHD behaviors. This study will help direct attention of policymakers to this population for mainstreaming them in public setting by modifying their behaviors. The author considers that this study may serve as starting point for casting greater light on this population in terms of motivating their learning, enriching the learning environment and inclusiveness in the teaching-learning process.

Typically, children with autism need special education skills to facilitate their learning. This task becomes more complex if they were diagnosed with behavioral disorders like attention deficit hyperactivity. This study focuses on this population of autism children diagnosed with ADHD behaviors. Usually, the strategy of mainstreaming children with autism is used to facilitate their learning and reduce the counter effect of any excessive behaviors. This study casts light on this problem by studying the effect of mainstreaming autism children diagnosed with ADHD disorder on reducing their ADHD behaviors. This study addresses and tries to answer the following question.

"How effective is mainstreaming autism children with normal children in reducing attention deficit hyperactivity ADHD behaviors?"

\section{Prior Studies}

The literature review of the related studies conducted by the researcher revealed no study directly associated with the problem addressed by the current study, and the studies reviewed mostly were focused on attention deficit hyperactivity disorder and its symptoms.

Suleiman (2015) conducted a study to identify teacher's perceptions regarding attention deficit hyperactivity disorder, and to reveal the impact of gender, experience with ADHD students, attendance of training courses, educational qualification, age and years of experience on teacher's perceptions about the disorder. The sample consisted of (102) male and female teachers at Yeba Educational District, Beni Sweif, Egypt. The researcher employed ADHD Disorder Recognition Scale Sciutto et al. (2000) translated and standardized by the researcher. 
Using the statistical methods appropriate to study question, results indicated that teachers' recognition of ADHD disorder is strongly poor $(\mathrm{M}=43.71 \%)$. Further, results revealed no statistical significant differences between males and females in ADHD recognition; as well as no statistically significant differences was found between those have and those haven't recognized ADHD disorder. Finally, there were differences between teachers who attended and those did not attend training courses regarding ADHD recognition in favor of attendants, and no differences were found in ADHD recognition attributed to academic qualification.

Ghusun (2011) sought to identify the impact of concept mapping on achievement and modification of attention deficit among special education students. The researcher used the experimental design with experimental and control groups. The sample was confined to 4th elementary graders in special education setting at Ninwa Governorate Center in 2010-2011. Participants were (18) students assigned to experimental ( $\mathrm{n}=8$ ) and control $(n=10)$ groups. The researcher developed instructional plans to teach grammar for both groups and 20-item achievement test. The Attention Deficit scale developed by Al Obeidi (1999) was adopted in the current study. Both instruments were validated by showing them to a group of judges. Reliability coefficient for the achievement test (0.90) was verified using Kuder-Richardson 20 (KR20) formula; and reliability (0.93) for the attention deficit scale was tested using half-split technique. Both reliability coefficient values considered appropriate. The tests were administered to both groups, and data collected were statistically treated using two independent samples. Results showed statistically significant differences in achievement on t test between means of the experimental group taught using concept mapping compared with the control group taught normally with differences being in favor of the experimental group and there was improvement in attention deficit in the experimental group. The researcher recommended employing conceptual mapping in education of special education children and suggested conducting further studies similar this study on science subject.

Similarly, Al Mafarj (2011) conducted a study for purpose of identifying the impact of pictured story and role playing on modification of attention deficit among special education students. The sample consisted of (28) male and female students assigned to experimental group $(n=9)$ taught using pictured story method and second experimental group $(n=10)$ taught using role playing method and the control group $(n=9)$ exposed to normal teaching. Equivalence was ensured among variables (age in months, reading score. GPA in the second primary grade, parental educational level, and posttest measurement of attention deficit). The researcher used the statistical methods including t test, difficulty coefficient, discriminatory power, Pearson correlation and Chi square). Statistical treatment of data revealed superiority of first and second experimental groups compared with the control group in modification of attention deficit.

Ahmad and Khalafallah (2011) designed a therapeutic program aiming at reducing attention deficit hyperactivity behavior among students with learning difficulty in the basic third and fourth grade levels in Khartoum and to investigate its effectiveness by the variables of gender $(\mathrm{M} / \mathrm{F})$, grade level (3rd, 4th), interaction between gender and grade level in reducing attention deficit hyperactivity behavior.

To achieve the study goal, the author employed the experimental pretest-posttest design with one group. The instruments used included Teachers' Estimate of Learning Difficulty Characteristics Inventory, Michael Best Scale for Identification Children with Learning Difficulty, Colored Progressive Matrices Test standardized for the Sudanese environment and ADHD Scale. The psychometric properties of such instruments were verified and were administered to a sample of 29 students $(\mathrm{M}=19, \mathrm{~F}=10)$ with learning difficulty attending the 3rd and 4th grade levels and diagnosed with ADHD disorder.

Using the statistical methods including Pearson Correlation, Cronbach Alpha, $t$ test, two way analysis of variance. Results confirmed effectiveness of the therapeutic program in reducing attention deficit hyperactivity behavior among students; and there were no statistically significant differences in the perceived improvement by gender, except on posttest measurement in favor of female students.

Results also showed no statistically significant differences in the perceived improvement by variable grade level

Patricial ad Lynne (2007) conducted a study to investigate teacher perceptions on students with attention deficit hyperactivity ADHD disorder. The researchers argued that ADHD behaviors first identified in classroom and 60 per cent of referrals were by teachers, indicating a significant part taken by teachers in early detection, diagnosis and identification of students with ADHD disorder. The purpose of this study was to identify teachers' perceptions about identification of students with ADHD disorder.

Ghanizadeh et al. (2006) conducted a study on perceptions and attitudes to attention deficit hyperactivity disorder for purpose of identify primary school teachers' awareness to ADHD disorder and their attitudes towards it. The study involved primary school teachers (196) in Sheraz City, Iran. The study used a scale to measure teachers' perceptions and attitudes to the disorder. Findings showed that primary school teachers held low perceptions on the ADHD disorder, where about 46.9 percent considered that ADHD of genetic and biological origin, 53.1 per cent viewed that parental overprotection caused the disorder. Similarly, the attitudes to ADHD disorder was low, where 64.8 per cent of teachers viewed that punishment styles applied on normal students should be used with disordered students; and 7706 per cent believed that disordered children face difficulties in 
their relations with peers. The study also found a statistically significant association between teachers' perceptions and attitudes to ADHD disorder. It was revealed that perceptions regarding the disorder were low and major resources included TV, radio, friends, relatives, journals and magazines.

Julie et al. (2006) concluded that despite there are huge evidence that there are social and academic difficulties with attention deficit hyperactivity ADHD children, teachers still lack the expertise of what they should do with them or what they must know. The paper summarizes evidence and information about the difficulties encountered with ADHD students, relationship with teachers, perceptions of teachers regarding ADHD disorder, and how to deal with it by preservice and in-service teachers. Specifically, in-service teachers need diagnosis skills to identify student ADHD behavior and get more alert to family conditions and symptoms of such population and to focus their attention on the relationship between students with ADHD behaviors and peers.

\section{Study Design:}

A quasi experimental design of two experimental and control groups was used in the current study. The study design consisting of nonequivalent or nonrandom groups with pre-posttest measurement, can be represented by the following diagram:

$$
\begin{array}{cccc}
\text { EG: } & \text { O1 } & \mathrm{X} & \mathrm{O} 1 \\
\mathrm{CG}: & \mathrm{O} 1 & & \mathrm{O} 1 \mathrm{O}
\end{array}
$$

Study Model, Source: developed by the author

Where;

EG: Experimental Group

CG: Control Group

O1: ADHD Scale (pretest-posttest measurement)

$\mathrm{X}$ : Treatment: (Mainstreaming Autism children with normal children population)

Instruments

Second: ADHD Scale

To identify the effectiveness of mainstreaming children with autism in normal classes, the researcher applied the attention deficit hyperactivity behavior scale, and measured its psychometric properties for using it to measure improvement among children.

\subsection{Validity of the Instrument}

To ensure validity, the instrument was sent to a group of specialized and experienced judges for validation. Their notes were taken into account and the instrument was modified accordingly in line with study goals and sense of honesty.

\subsection{Procedures}

The necessary official approvals were duly ensures.

Participants were randomly assigned to both experimental and control groups.

Participants were administered the Attention Deficit Hyperactivity ADHD Behavior Scale as a pretest of the experimental group behavior compared with the control group. .

Experimental group children were mainstreamed with the control group (normal children)

the Attention Deficit Hyperactivity ADHD Behavior Scale was reapplied as a posttest of the experimental group behavior compared with the control group.

Appropriate statistical analyses were conducted.

Conclusion, result discussion, and recommendation based on the study results.

\subsection{Statistical Methods}

To achieve the study goals and answer questions, means and standard deviations of respondent rating in the experimental and control groups. Paired Samples Test was conducted to for the experimental and control groups to identify differences on the pretest and posttest measurements.

\section{Results}

- How effective is mainstreaming autism children with normal children population in reducing attention deficit hyperactivity behaviors?

To answer this question, means and standard deviations were computed for values given by the pretest and posttest measurement on the experimental and control groups. Further, an Independent Sample T-Test was applied on the independent samples to reveal any differences between the two groups on pretest and posttest measurements as shown by the following tables.

Similarly, Paired sample T-Test was applied on the paired samples to identify any differences between pretest and 
posttest means for each group to measure the effect on reduced ADHD as shown by table below.

Equivalence of Groups, Independent Sample T-Test to identify group equivalence in reducing ADHD behavior on the pretest $(\mathrm{n}=60)$

Table 1. Independent Sample T-Test to identify group equivalence in reducing ADHD behavior on the pretest

\begin{tabular}{|l|l|l|l|l|l|}
\hline Group & $\mathrm{M}$ & $\mathrm{SD}$ & $\mathrm{T}$ & Freedom Degrees & $\alpha$ \\
\cline { 1 - 4 } Control & 3.4200 & .11715 & 1.651 & 58 & .104 \\
\hline Experimental & 3.4683 & .10945 & & & \\
\hline
\end{tabular}

The table 1 shows insignificantly negligible $(t)$ values at $(\alpha=.05)$ on pretest measurement, indicating equivalence between the experimental and control groups on pretest.

Results from Independent Sample T-Test for identifying differences between groups in reducing ADHD behavior on the posttest $(\mathrm{n}=60)$

Table 2. T-Test for identifying differences between groups in reducing ADHD behavior on the posttest

\begin{tabular}{|l|l|l|l|l|l|}
\hline Group & M & SD & T Value & Freedom Degree & Statistical Significance \\
\hline Control & 2.6533 & 0.16132 & 3.476 & 58 & 0.01 \\
\hline Experimental & 2.7967 & 0.15808 & & & \\
\hline
\end{tabular}

Table 2 shows statistically significant $(t)$ value at $(\alpha=0.05)$ between the experimental versus control groups on the pretest measurement, where differences were in favor of the experimental group. It was noticed that the attention deficit hyper activity ADHD behavior decreased among student in this group on the posttest compared with the control group, meaning that the hyper activity of children has become moderate and balanced with the teaching process.

Paired Samples Test applied on the paired samples to identify differences on pretest and posttest of the experimental versus control group regarding reduced ADHD behavior

Table 3. paired Test differences on pretest and posttest of the experimental versus control group regarding reduced ADHD behavior

\begin{tabular}{|l|l|l|l|l|l|l|}
\hline Group & Measurement & M & SD & T Value & Freedom Degrees & $\begin{array}{l}\text { Statistical } \\
\alpha\end{array}$ \\
\cline { 1 - 5 } Control & Pretest & 3.42 & .12 & 20.72 & 29.0 & 0.00 \\
\cline { 2 - 4 } & Posttest & 2.65 & .16 & & & \\
\cline { 1 - 4 } Experimental & Pretest & 3.47 & .11 & 18.25 & 29.0 & 0.00 \\
\hline
\end{tabular}

The above table shows statistically significant differences on the pretest and posttest for both groups on reducing attention deficit hyperactivity ADHD behavior, where $(\mathrm{t})$ value for the experimental group was at (18.25), and significant at (0.000) with differences being in favor of the posttest measurement. Comparatively, $(\mathrm{t})$ value for the control group was (20.72) and significant at (0.000) with differences being in favor of the posttest measurement.

Results demonstrate perceivable reduction from (20.72) to (18.25), implying improved ADHD behavior of the mainstreamed group.

To identify effectiveness extent of mainstreaming children with autism in normal children in reduction of attention deficit hyperactivity ADHD behavior ANCOVA test was applied as shown by the following table. Results from ANCOVA test to identify differences between groups in reducing ADHD behavior on the posttest as covariate

Table 4. Differences between groups in reducing ADHD behavior on the posttest as covariate

\begin{tabular}{|l|l|l|l|l|l|}
\hline & Total Squares & Freedom Degrees & Means Squares & F Value & Statistical Significance \\
\hline Group & 0.314 & 1 & 0.314 & 12.157 & .001 \\
\hline Covariate & 0.07 & 1 & 0.07 & 0.274 & 0.603 \\
\hline Error & 10472 & 57 & 0.026 & & \\
\hline Adjusted Error & 10788 & 59 & & & \\
\hline
\end{tabular}

The previous table shows statistically significant differences at $(0.05)$ by group, where differences were in favor of the experimental group. Additionally, the table showed no difference in reduced ADHD behavior on the pretest confirming equivalency between the two groups on the pretest measurement.

This result implies that the perceived improvement in the experimental group was caused by the mainstreaming strategy with statistical significance $(0.603)$ on the covariate pretest compared with $(0.001)$ for the whole group indicating positive effect of the mainstreaming strategy.

Result from the current study is in agreement with findings revealed by Al Mafarji (2011) that supported superiority of first and second experimental groups over the control group in modification of attention deficit. Similarly, is in agreement with Ahmad and Khalafallah (2011) that confirmed effectiveness of the therapeutic program with a statistical significance in reducing attention deficit hyperactivity among students. 


\section{Recommendations}

1- Specialized centers and professionals need to take care of learning difficulties of ADHD children .

2- Develop and activate instructional trip programs in all centers taking care of children with learning difficulties. Evoke the awareness of teachers to the consequences of attention deficit hyperactivity ADHD and qualify them to be able to deal with ADHD children because they are the first level of communication with learning difficulties.

\section{Limitations}

The generalizeability of results from the current study are limited to population selected to investigate the effect of mainstreaming autism children with normal population on reduced ADHD behaviors. The expected results will hold viable to similar populations depending on the practical implications.

\section{References}

Ahmad, Abelbaki Dafaallah \& Khalafallah, Kawthar Jamal Eddin. (2011). Effectiveness of a Therapeutic Program in Improving Attention Deficit/Hyperactivity among Basic Stage Children with Learning Difficulty in Khartoum. Published on Individuals with Disabilities Forum, Gulf Children with Special Needs.

AL Mafarji, Orwa Adnan Shett. (20110. The Impact of Pictured Story and Role Playing in modification of attention deficit among Special Education Children. Unpublished Master Thesis. Faculty of Basic Education, University of Mosel.

Ghanizadeh, A., Bahredar, M. J., \& Moeinia, S. R. (2006). Recognitioon and attitudes towards attention deficit hyperactivity disorder among elementary school teachers. Patient Education and Counseling, 63(1), 84-88.

Ghusun, Khaled Al Sharif. (2011). Impact of Using Concept Mapping on Modification of Attention Deficit among Special Education Children. Basic Education College Research Journal. Vol. 11, Iss. 2, PP63-98.

Julie M. Kos , Amanda L. Richdale and David A. Hay (2006). Children with Attention Deficit Hyperactivity Disorder and their Teachers: A review of the literature, International Journal of Disability Development and Education, 53(2), 147-160

Mohammad, Hosam Eddin. (2013). Effectiveness of Field Trip Model in Apprehension of Science Concepts and Develop Some Inquiry Scientific Curiosity Skills among Middle School Students. Master Thesis, Tanta University, Egypt.

Patricia Mahar, and Lynne Chalmers (2007). Teachers' Perceptions of Students Diagnosed with ADHD, National Forum of Applied Educational Research Journal, Vol 20, Num 3, 2007.

Suleiman, Mohammad Sayed Said. (2015). Teachers' Perceptions of Attention Deficit Hyperactivity Disorder in the Elementary Stage. Islamic University Journal for Psychological and Educational Studies, Vol. 23, Iss. 1, PP98-121.

Zaitoun, Hasan Hussein. (2003). Instructional Field Trip Model: New Approach for Developing TeachingLearning Methods in our Schools. Cairo, World of Books.

Zaitoun, Hasan Hussein. (2003). Teaching to Think: Application Vision to enhance Thinking Mind. Cairo, World of Books. 